Research Paper

\title{
Environmentally relevant concentrations of microplastics influence the locomotor activity of aquatic biota
}

\author{
Tao Sun ${ }^{\text {a,d }}$, Junfei Zhan ${ }^{\text {a,d }}$, Fei Li ${ }^{\text {a,c }}$, Chenglong Ji ${ }^{\text {a,b,c }}$, Huifeng $\mathrm{Wu}^{\text {a,b,c, * }}$ \\ ${ }^{a}$ CAS Key Laboratory of Coastal Environmental Processes and Ecological Remediation, Yantai Institute of Coastal Zone Research (YIC), Chinese Academy of Sciences \\ (CAS); Shandong Key Laboratory of Coastal Environmental Processes, YICCAS, Yantai 264003, PR China \\ ${ }^{\mathrm{b}}$ Laboratory for Marine Fisheries Science and Food Production Processes, Qingdao National Laboratory for Marine Science and Technology, Qingdao 266237, PR China \\ ${ }^{\mathrm{c}}$ Center for Ocean Mega-Science, Chinese Academy of Sciences (CAS), Qingdao 266071, PR China \\ ${ }^{\mathrm{d}}$ University of Chinese Academy of Sciences, Beijing 100049, PR China
}

\section{A R T I C L E I N F O}

Editor: Dr. R Teresa

\section{Keywords:}

Microplastics

Aquatic biota

Locomotor activity

Environmentally relevant concentrations

Meta-analysis

\begin{abstract}
A B S T R A C T
The occurrence of microplastics (MPs) in various marine and freshwater matrices has attracted great attention. However, the effect of MPs in natural environment on the locomotor performance of aquatic biota is still controversial. Therefore, this meta-analysis was conducted, involving 116 effect sizes from 2347 samples, to quantitatively evaluate the alteration in locomotor behavior of aquatic organisms induced by MPs at environmentally relevant concentrations $(\leq 1 \mathrm{mg} / \mathrm{L}$, median $=0.125 \mathrm{mg} / \mathrm{L}$ ). It was shown that MP exposure significantly inhibited the average speed and moved distance of aquatic organisms by $5 \%$ and $8 \%(p<0.05)$, respectively, compared with the control, resulting in an obvious reduction of locomotor ability by $6 \%(p<0.05)$. Egger's test indicated that the results were stable without publication bias $(p>0.05)$. The complex influence of MPs on the locomotor ability were characterized through random-effects meta-regression analyses, presenting size-, time-, concentration-dependent manners and multi-factors interactions. In addition, several physiological changes, including energy reserve reduction, metabolism disorder, gut microbiota dysbiosis, inflammation response, neurotoxic response, and oxidative stress, of aquatic organisms triggered by MP exposure at environmentally relevant concentrations were also provided, which might account for the MPs-induced locomotor activity decline.
\end{abstract}

\section{Introduction}

As an important sink, the aquatic environment has continually accumulated a large amount of pollutants, threatening the health and viability of aquatic organisms (Barboza et al., 2018a; Alomar et al., 2020; Patel et al., 2020). Among these pollutants, the ubiquitous microplastics (MPs, $<5 \mathrm{~mm}$ in size) have attracted global concerns (Li et al., 2020a; Miller et al., 2020). Numerous studies focus on the potential toxicity of MPs to aquatic organisms (Gambardella et al., 2017; Ziajahromi et al., 2018; De Felice et al., 2019; Naidoo and Glassom, 2019; Costa et al., 2020; Horn et al., 2020; Hu et al., 2021). However, due to the inconsistency in study design, and the mismatch between MP concentrations selected in laboratory studies and those monitored in realistic environments, the toxicity of MPs in the natural environment is still debatable (Burns and Boxall, 2018; Bucci et al., 2020).
For many species, behavioral alterations represent the first response to environmental stressors (Wong and Candolin, 2015). These intentional or unintentional behavioral changes directly influence the fitness indicators (e.g. growth, survival and reproduction), and play key roles in determining how individuals cope with the changing environment (Saaristo et al., 2018; Sievers et al., 2019). The locomotor activity quantified by the average speed and moved distance, as one of the most investigated behavioral responses of aquatic organisms to MP exposure, has been increasingly used as a sensitive indicator for assessing the impact of MPs (Chen et al., 2017a; Limonta et al., 2019; Zhang et al., 2020a). Recently, the contrary effects of MPs on the locomotor activity of aquatic biota at environmentally relevant concentrations have been widely reported, such as the hyperactive swimming behavior (Chen et al., 2020) versus the increased static duration (Bringer et al., 2020), and these arguments are confusing the public and the scientific

\footnotetext{
* Corresponding author at: CAS Key Laboratory of Coastal Environmental Processes and Ecological Remediation, Yantai Institute of Coastal Zone Research (YIC), Chinese Academy of Sciences (CAS); Shandong Key Laboratory of Coastal Environmental Processes, YICCAS, Yantai 264003, PR China.

E-mail address: hfwu@yic.ac.cn (H. Wu).
} 
community.

Moreover, many studies indicated that MPs ingested by aquatic organisms could be retained and accumulated in the gastrointestinal tract, which could trigger a series of adverse physiological reactions, such as energy reserve reduction (Yin et al., 2019), metabolism disorder (Zhao et al., 2020), gut microbiota dysbiosis (Wan et al., 2019), inflammation response (Jin et al., 2018), neurotoxic response (Tang et al., 2020) and oxidative stress (Barboza et al., 2018b). These adverse effects are closely related to energy supply, physical health and behavior modulation of aquatic organisms, suggesting the potential locomotor alteration induced by MPs (Mattsson et al., 2015; Limonta et al., 2019; Pirsaheb et al., 2020). Therefore, based on the current literature, we hypothesize that MPs can be ingested and accumulated by aquatic organisms, and subsequently cause toxic effects, thereby potentially alter the locomotor activity. However, there is still a lack of evidence-based assessment on the positive, negative or neutral effects of MPs on the locomotor activity of aquatic organisms at environmentally relevant concentrations.

Promisingly, meta-analysis is particularly powerful in integrating the conflicting findings with the same topic to determine a general trend and obtain a reliable estimator (Gurevitch et al., 2018). For example, Arciga and Soliman (2020) combined the existing positive/negative/neutral evidence by meta-analysis, identifying that MP exposure could reduce the growth rate of aquatic organisms. Based on the strong statistical power of meta-analysis, therefore, this work was conducted, aiming to (i) quantitatively evaluate the biological effect of MPs at environmentally relevant concentrations on the locomotor activity of aquatic organisms; (ii) explore the factors that may influence the effect of MPs; (iii) delineate potential mechanisms underlying MPs-induced locomotor activity decline. The biological effects of MPs on aquatic biota can be generally divided into two types: particle effect and chemical effect. The former is due to the direct interaction between MPs and organism tissues, while the latter is caused by the transfer of pollutants adsorbed on the surface of MPs or the leaching of plastic additives/monomers (Fossi et al., 2014; Pedà et al., 2016; Limonta et al., 2019). In this study, the effects of MPs refer to both particle effect and leachate-induced potential chemical effect.

\section{Materials and methods}

\subsection{Literature retrieval}

Following to the Cochrane Handbook v.6.1 (Higgins et al., 2020), three databases including Web of Science Core Collection, the Cochrane Library and Medline were systematically searched, using the terms and modifiers: "plastic*, debris, behavio*, alter*, change*, locomot*, speed, velocity, distance, swim*, mov*, aquatic biota, aquatic organism, marine, sea, ocean, freshwater. Gray literature, such as conference papers, dissertations and listed references, were also checked via Index to Scientific and Technical Proceedings and Baidu Scholar.

\subsection{Inclusion criteria}

The inclusion criteria for this meta-analysis were as follows: (i) original research paper; (ii) designed the control group; (iii) documented the effects of MPs on average speed and moved distance of aquatic organisms at environmentally relevant concentrations $(\leq 1 \mathrm{mg}$ / L) (Leslie et al., 2017; Besseling et al., 2019; Han et al., 2020; Garcés-Ordóñez et al., 2020); (iv) the effect was induced by MPs only (i. e. not combined exposure with other contaminants); (v) reported the mean, sample size, standard deviation $(S D)$ /standard error (SE) for control and treatment groups.

\subsection{Data extraction}

After final screening, a total of 17 studies from 468 retrieved records were included in this meta-analysis (Table S1). The following information were extracted from included studies: (i) the first author; (ii) publication year; (iii) the tested species; (iv) the selected morphology, composition, size and concentration of MPs, and exposure duration; (v) the endpoint with sample size, mean, and SD/SE. The Getdata Graph Digitizer v.2.24 software (http://getdata-graph-digitizer. $\mathrm{com} /$ ) was used to measure the data presented in figures (Mazidi et al., 2017). The extracted data were cross-checked by two researchers, and any disagreement was resolved by discussion or consultation with the third researcher.

\subsection{Data analysis}

The effect size (ES) of MPs on the locomotor activity of aquatic biota was evaluated using the response ratio $(R R)$ (Hedges et al., 1999; Sievers et al., 2019). The $E S$ and its variance ( $v$ ) were calculated by formulas (1) and (2), respectively.

$E S=R R=\operatorname{In}\left(\frac{x_{t}}{x_{c}}\right)=\operatorname{In}\left(x_{t}\right)-\left(x_{c}\right)$

$v=\frac{\left(S D_{t}\right)^{2}}{n_{t} x_{t}^{2}}+\frac{\left(S D_{c}\right)^{2}}{n_{c} x_{c}^{2}}$

where $x_{c}, S D_{c}$ and $n_{c}$ were the arithmetic mean of the locomotor activity, standard deviation of the mean and the replicate number, of the control group, respectively. And $x_{t}, S D_{t}$ and $n_{t}$ represented the arithmetic mean, standard deviation of the mean and the replicate number, of the MPstreated group, respectively.

Then, the overall $E S\left(\overline{E S^{*}}\right)$ and its $S E\left(\overline{S E^{*}}\right)$ were calculated by formulas (3) and (4), respectively.

$\overline{E S^{*}}=\left(\sum_{i=1}^{k} w_{i}^{*} E S_{i}\right) /\left(\sum_{i=1}^{k} w_{i}^{*}\right)$

$\overline{S E^{*}}=1 /\left(\sum_{i=1}^{k} w_{i}^{*}\right)^{1 / 2}$

where $i$ and $k$ denoted $i$ th endpoint and the number of included endpoints, respectively. And $w_{i}^{*}$ was the reciprocal of the total variance of $E S$, which was calculated using the formula (5).

$$
\begin{aligned}
& w_{i}^{*}= 1 /\left\{v_{i}+\left[\sum_{i=1}^{k}\left(E S_{i}^{2} / v_{i}\right)-\left(\sum_{i=1}^{k}\left(E S_{i} / v_{i}\right)\right)^{2} / \sum_{i=1}^{k}\left(1 / v_{i}\right)-(k\right.\right. \\
&\left.-1)] /\left[\sum_{i=1}^{k}\left(1 / v_{i}\right)-\sum_{i=1}^{k}\left(1 / v_{i}\right)^{2} / \sum_{i=1}^{k}\left(1 / v_{i}\right)\right]\right\}
\end{aligned}
$$

A significant effect of MPs on the locomotor activity of aquatic biota was determined if the bootstrapped (64,999 iterations) 95\% confidence interval of $\overline{E S^{*}}$ did not overlap with zero (Chen et al., 2017b; De Stefano and Jacobson, 2018; Cole, 2020).

The publication bias was visually detected by the funnel plot that was produced by Stata v.12.0 software (StataCorp, College Station, USA) (Higgins et al., 2020), and quantitatively assessed using the Egger's test (Egger et al., 1997). The random-effects meta-regression was employed via the metareg command in Stata to explore the potential factor that might influence the effect of MPs (see Chapter 10.11.4 of the Cochrane Handbook). The statistical significance was set at $\alpha=0.05$.

\section{Results and discussion}

\subsection{MPs-induced locomotor activity decline in aquatic biota}

In this meta-analysis, aquatic organisms showed a significant decrease in locomotor activity by $6 \%$ after exposure to MPs at environmentally relevant concentrations $(\leq 1 \mathrm{mg} / \mathrm{L}$, median $=0.125 \mathrm{mg} / \mathrm{L}$ ) 
compared with the control ( $p<0.05)$, which was manifested as the obvious reductions of average speed and moved distance by $5 \%$ and $8 \%$, respectively $(p<0.05)$ (Fig. 1$)$. The Egger's test indicated that this retrospective analysis was robust without evident publication bias $(p>0.05)$ (Fig. 2).

Locomotor behaviors play integral roles in feeding and social activities of aquatic organisms throughout their lifespan (Colwill and Creton, 2011; da Silva Souza et al., 2020). The locomotion speed was closely associated with the predator-avoidance behavior (Pang et al., 2014; Yin et al., 2019). The decrease of speed caused by MPs suggested that aquatic organisms ingesting MPs might not only reduce predation, but also be exposed to high risk of being preyed upon. Rist et al. (2017) reported that the microalgae ingestion rate of Daphnia magna significantly decreased by $21 \%$ after exposure to $1 \mathrm{mg} / \mathrm{L}$ polystyrene (PS) MPs for $24 \mathrm{~h}$. Similarly, MPs-induced inhibition of feeding activity was also observed in Neomysis japonica, with a maximum of $20 \%$ at $250 \mu \mathrm{g} / \mathrm{L} \mathrm{PS}$ MPs for $0.5 \mathrm{~h}$ (Wang et al., 2020). As proposed by Rotjan et al. (2019), MPs were barriers to food intake. In terms of the predation risk, Seuront (2018) evaluated the effect of environmentally relevant MP leachates on the predator (Carcinus maenas) - prey (Littorina littorea) interaction, indicating the increase of vulnerability and the decrease of escape response of L. littorea. In addition, the moved distance was a reflection of the explorative ability, and its reduction implied that after MP exposure, aquatic organisms tended to stay closer together in small-scale areas against the harsh environment, that was, the shoaling behavior (Gerlai, 2014; Mattsson et al., 2015; Wang et al., 2020). Correspondingly, the shoaling behaviors of zebrafish (Danio rerio) and black rockfish (Sebastes schlegelii) induced by MPs at environmentally relevant concentrations were revealed by Sarasamma et al. (2020) and Yin et al. (2019), respectively, which was reflected in the average inter-fish distance significantly decreased by 7-74\% compared with control groups (Fig. 3). Therefore, the MPs in the natural environment could influence the locomotor activity of aquatic organisms and further produced a negative effect on their hunting behavior and exploration competence.

\subsection{Factors influencing the biological effect of MPs}

Previous studies on other endpoints suggested that the biological effects of MPs were influenced by multiple abiotic and biotic factors, such as the size-dependent reactive oxygen species (ROS) generation in the haemocytes of Tegillarca granosa (Shi et al., 2020), the dose-response relationship between MP concentration and dimethylsulfide production in Tigriopus japonicus (Yu et al., 2020), and the highly variable impacts of MPs on the growth of different aquatic biota (Foley et al., 2018). Consistently, a size-dependent pattern of locomotor activity was reported by Chen et al. (2017a) through investigating the effects of two sizes of MPs $(0.05 \mu \mathrm{m}$ and $50 \mu \mathrm{m})$ on the locomotor activity of zebrafish. Results showed that $0.05 \mu \mathrm{m}$ MPs significantly suppressed the larval locomotion by $22 \%$, while $50 \mu \mathrm{m}$ MPs did not exhibit obvious influence. However, whether the biological effects of MPs are affected by other factors (e.g. MP composition, concentration, and exposure duration), and to what extent these laboratory-based findings can be applied to evaluate the risk of MPs in the natural environment are still unclear. In this meta-analysis, a relatively complex exposure framework (e.g. various species, different concentrations, and dissimilar sizes) was established by combining diverse individual studies. Therefore, the time is ripe for understanding the mode of MP action by exploring the factors that may influence the biological effect of MPs on the locomotor activity of aquatic biota.

In this study, the univariate meta-regression analyses demonstrated that the effects of MPs on the locomotor activity presented size-, timeand concentration-dependent manners $(p<0.05)$ (Fig. 4a-c). Specifically, the locomotor performance of aquatic organisms enhanced significantly with the increase of MP size (Fig. 4a), suggesting that the smaller MPs could induce a stronger behavioral toxicity. The increased toxicity might be due to the higher availability of the smaller MPs (Jeong et al., 2016; Botterell et al., 2019). Interestingly, the locomotor activity of aquatic organisms increased significantly with the extension of exposure time (Fig. 4b), which challenged some previous observations on other endpoints, such as the negative relationship between lysosomal membrane stability and exposure duration (von Moos et al., 2012). This inconsistency could be explained by (i) the biological effect of MPs was closely related to the selected endpoint (Wright et al., 2013a; Anbumani and Kakkar, 2018); (ii) organisms had certain adaptability and self-healing potential. Prolonging exposure time enabled organisms to adapt and respond to MP stress, and this adaptive response could strengthen the biological performance by overcompensating for MPs-induced homeostasis disruption (i.e. the hormetic effect) (Calabrese, 2014). However, it could be speculated that if the exposure duration was extended above a certain threshold, the locomotor activity would be inhibited since MPs could impede the feeding and continuously reduce the energy gained (Cole et al., 2015). Expectedly, the locomotor ability declined obviously with the increase of exposure concentration (Fig. 4c), as the higher the MP concentration, the greater the adverse effect of induction (Zhang et al., 2019a; Tunali et al., 2020). The concentration-dependent effect of MPs presents a very interesting hypothesis, that is, when the concentration of MPs is very low, positive effects induced by MPs may be observed, which is particularly important for the risk assessment of MPs in relatively clean aquatic environment. However, this hypothesis needs further verification, due to the complex

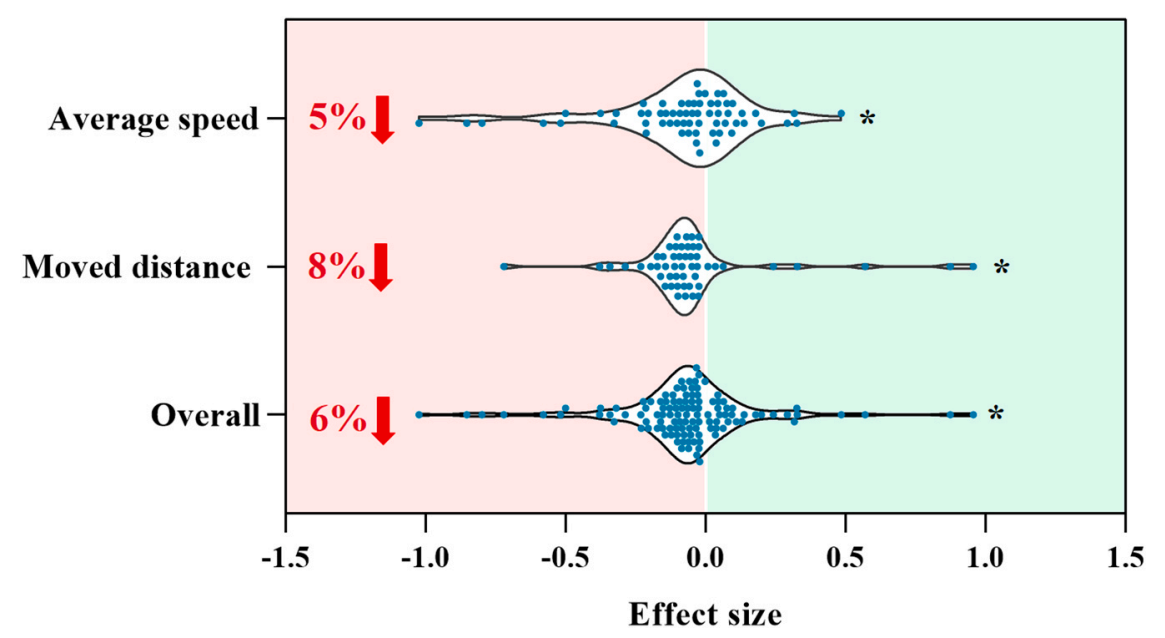

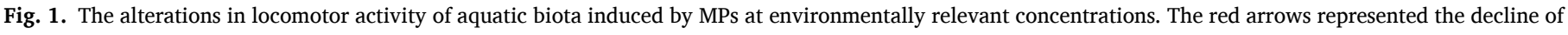
locomotor performance. The asterisk $(*)$ indicated statistical difference $(p<0.05)$ between control and MP treatment groups. 
a

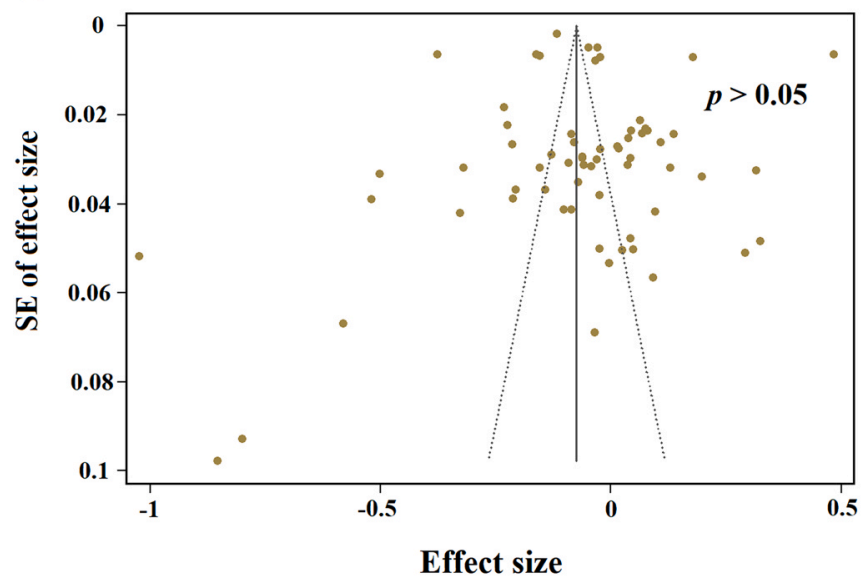

b

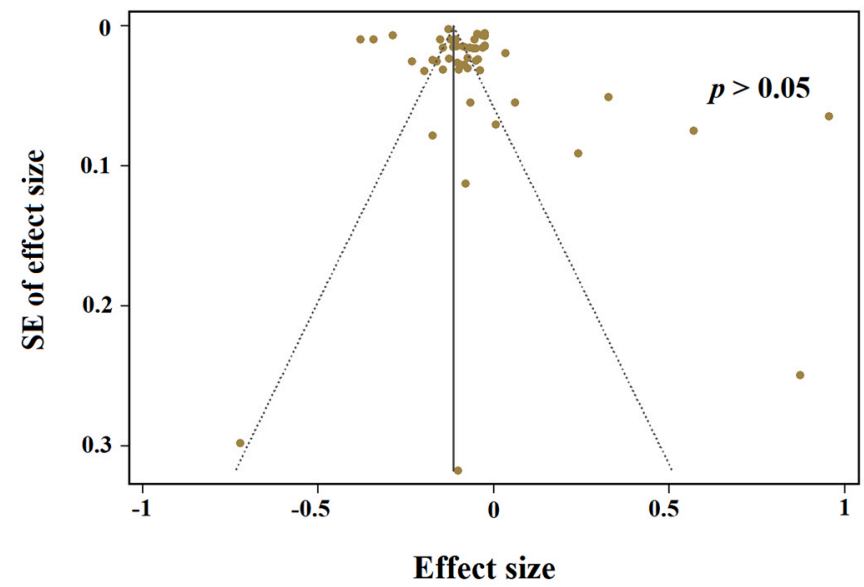

C

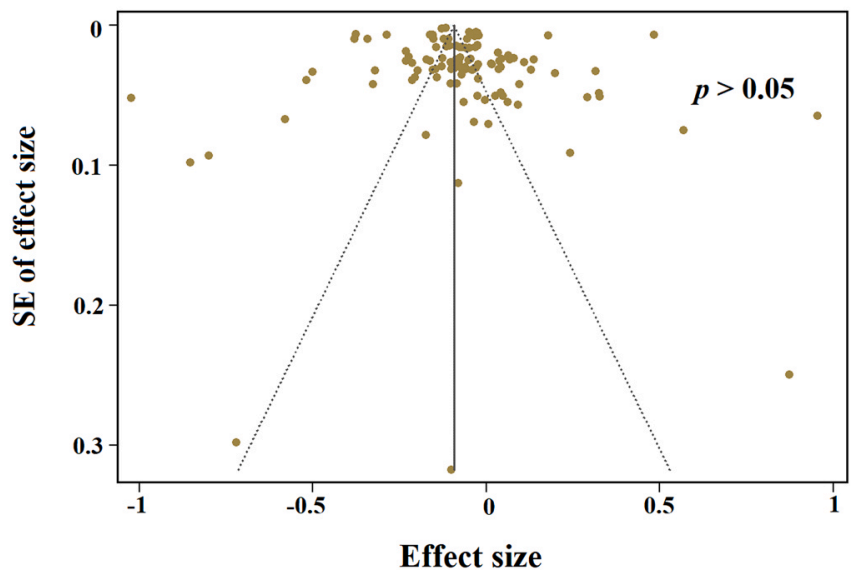

Fig. 2. Funnel plots of publication bias assessments. Sub-figures (a), (b) and (c) represented the publication bias assessments for average speed, moved distance and all endpoints, respectively. There was no obvious publication bias when the $p$-value was greater than 0.05 (Egger et al., 1997).

action mode of MPs. Therefore, based on this meta-analysis, we call for more future studies to focus on the effects of MPs at low concentrations, especially the potential dose-response relationship. Furthermore, the impact of MPs on the locomotor activity of tested species did not exhibit species specificity, highlighting the widespread influence/threat/risk of MPs on the aquatic environment. In addition, the multivariate meta-regression analyses revealed the complex action mode of MPs on

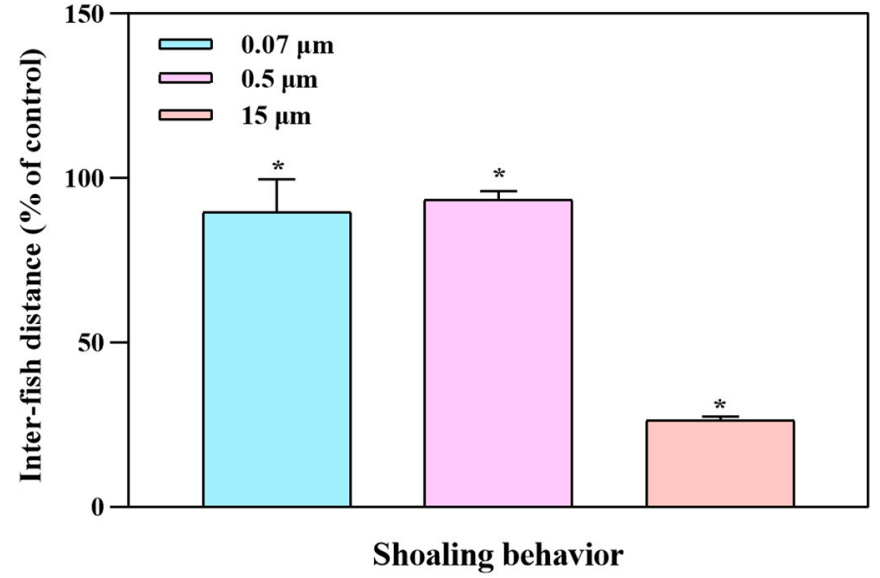

Fig. 3. The shoaling behavior of aquatic organisms induced by MPs at environmentally relevant concentrations. Data were extracted from Sarasamma et al. (2020) and Yin et al. (2019). The asterisk (*) denoted the significant difference $(p<0.05)$ of inter-fish distance between the control and MP treatment groups in the original paper.

the locomotor performance of aquatic organisms, manifested as the interaction of multiple factors (Fig. 4d). Currently, the interactions between MPs and other contaminants, such as organic pollutants (Guven et al., 2018; Li et al., 2020b; Nobre et al., 2020), trace metals (Barboza et al., 2018a; Banaee et al., 2019; S1kdokur et al., 2020) and antibiotics (Fonte et al., 2016; Zhang et al., 2019b; Zhou et al., 2020), have been widely concerned. However, the interactions among MP characteristics, and between MPs and species have received limited attention, resulting in the mismatch and knowledge gap between the selected exposure condition and the complicated natural environment (Burns and Boxall, 2018; Akdogan and Guven, 2019; de Ruijter et al., 2020). Therefore, the interaction of multiple factors is necessary to be considered in the future MP relevant toxicity studies to address the mismatch and knowledge gap.

Additionally, methodological diversity is one of the potential contributors of variations between studies (Higgins et al., 2020). In this study, therefore, methodologies adopted by the locomotor activity assay were evaluated, indicating multiple inconsistencies, primarily embodied in six aspects: acclimation, test sequence, test paradigm, test time, test procedure, and data analysis (Table 1). These inconsistencies in study design could cause potential bias in assessing the biological effects of MPs (Savović et al., 2012; Fok et al., 2020). For example, in the test environment, unacclimated animals might be stimulated, which contributed to potential locomotor alternation. Similarly, different test time might produce different results, as circadian rhythm variation was observed in the locomotor activity (Vera et al., 2009; Ebrahimi et al., 2017; Krylov et al., 2020). Moreover, the absence of information on experimental methods (e.g. only four studies reported the test time) posed a challenge to the inter-study comparison of the effects of MPs. Therefore, it is highly recommended that a consistent and relatively standardized proposal, characterized (but not limited) by designing an adaptation period, giving priority to the behavior assay, using the same test paradigm, adopting the circadian rhythm matched test time, employing professional analysis software, and reporting detailed test information, should be considered for future studies to obtain less biased results and increase the comparability between studies.

\subsection{Several physiological changes after exposure to MPs}

Recently, some studies have reported several physiological changes, including energy reserve reduction, metabolism disorder, gut microbiota dysbiosis, inflammation response, neurotoxic response, and oxidative stress, of aquatic organisms triggered by MP exposure at 
a

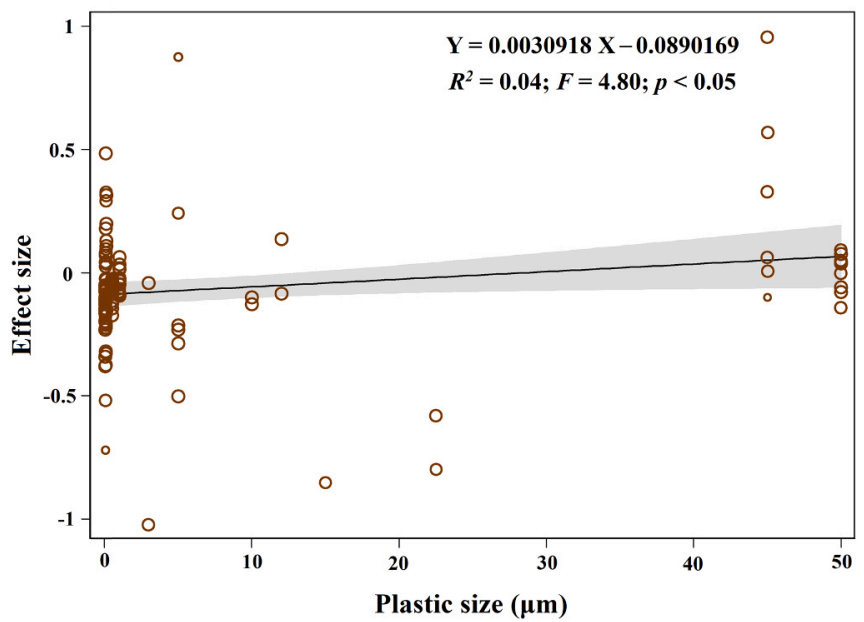

C

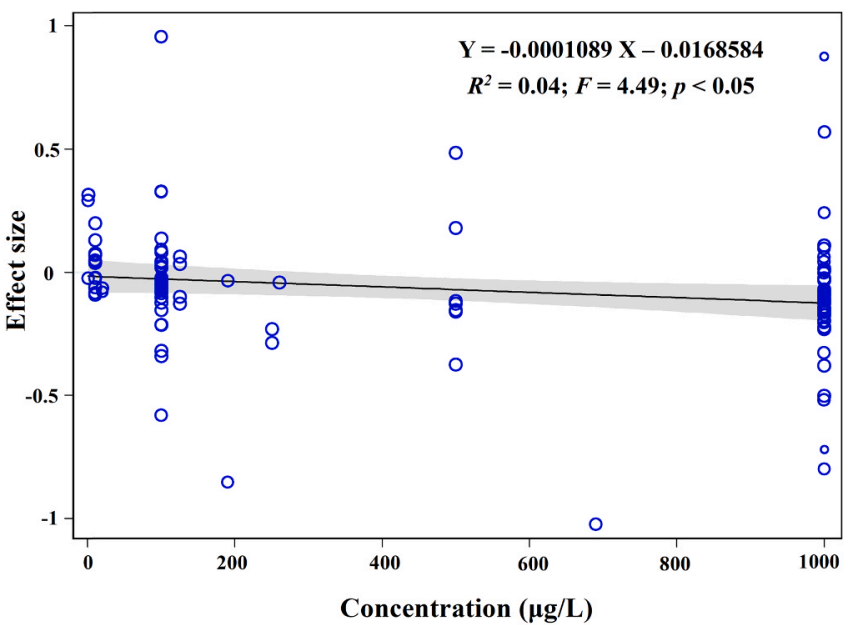

b

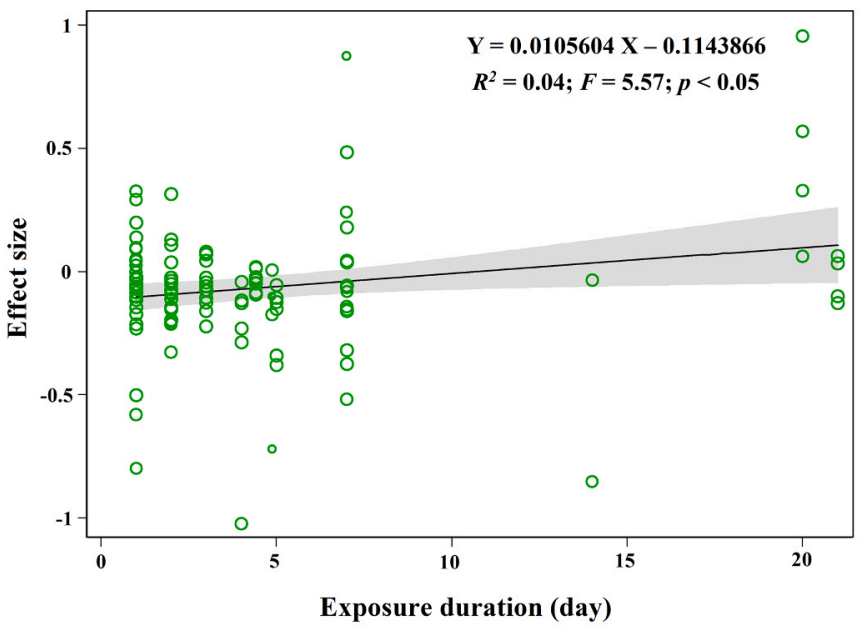

d

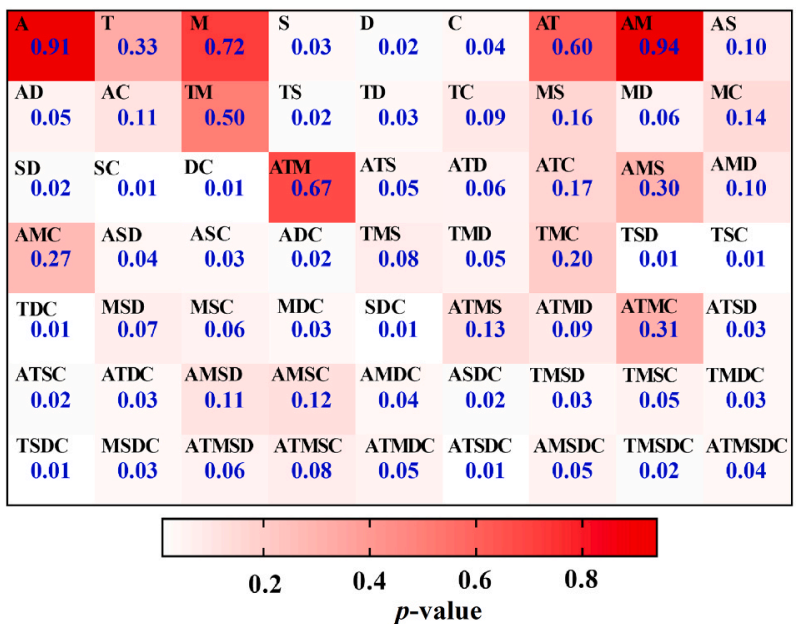

Fig. 4. The random-effects meta-regression analyses of factors that potentially influence the biological effects of MPs. The $p$-value less than 0.05 indicated that this factor contributed to the effect of MPs. The capital letters of A, T, M, S, D, and C in the sub-figure (d) represented the tested animals, selected MP composition, morphology, size, exposure duration, and exposure concentration, respectively.

Table 1

The locomotor activity assay design of included studies.

\begin{tabular}{lllllll}
\hline Included study & Acclimation (min) & Test sequence & Test paradigm & Test time & Test procedure & Behavior analysis technology \\
\hline Barboza et al., 2018a & - & First & Against water flow & - & ME $\rightarrow \mathrm{SR} \rightarrow \mathrm{DA} \rightarrow \mathrm{OR}$ & - \\
Bringer et al., 2020 & - & First & Free swimming & - & $\mathrm{ME} \rightarrow \mathrm{SR} \rightarrow \mathrm{DA} \rightarrow \mathrm{OR}$ & ImageJ v.1.52a software \\
Chen et al., 2017a & - & First & Free swimming & - & $\mathrm{ME} \rightarrow \mathrm{SR} \rightarrow \mathrm{DA} \rightarrow \mathrm{OR}$ & EthoVision XT 10 software \\
Chen et al., 2020 & 5 & First & Free swimming & - & $\mathrm{ME} \rightarrow \mathrm{AC} \rightarrow \mathrm{SR} \rightarrow \mathrm{DA} \rightarrow \mathrm{OR}$ & EthoVision XT software \\
De Felice et al., 2019 & 30 & First & Free swimming & - & $\mathrm{ME} \rightarrow \mathrm{AC} \rightarrow \mathrm{SR} \rightarrow \mathrm{DA} \rightarrow \mathrm{OR}$ & ImageJ plugin Animal Track \\
Gambardella et al., 2017 & - & Second & Free swimming & - & $\mathrm{ME} \rightarrow \mathrm{MA} \rightarrow \mathrm{DA} \rightarrow \mathrm{OR}$ & Swimming Behavioral Recorder system \\
Gambardella et al., 2018 & - & Second & Free swimming & - & $\mathrm{ME} \rightarrow \mathrm{MA} \rightarrow \mathrm{DA} \rightarrow \mathrm{OR}$ & Swimming Behavioral Recorder system \\
Gu et al., 2020 & 20 & First & Free swimming & - & $\mathrm{ME} \rightarrow \mathrm{AC} \rightarrow \mathrm{DA} \rightarrow \mathrm{OR}$ & Zebralab Video-Track system \\
Hu et al., 2021 & - & First & Free swimming & - & $\mathrm{ME} \rightarrow \mathrm{DA} \rightarrow \mathrm{OR}$ & Zebralab Video-Track system \\
Limonta et al., 2019 & - & First & Free swimming & - & $\mathrm{ME} \rightarrow \mathrm{SR} \rightarrow \mathrm{DA} \rightarrow \mathrm{OR}$ & El Temps v.1.179 software \\
Qiang and Cheng, 2019 & 10 & First & Free swimming & - & $\mathrm{ME} \rightarrow \mathrm{AC} \rightarrow \mathrm{DA} \rightarrow \mathrm{OR}$ & Zebralab Video-Track system \\
Sarasamma et al., 2020 & $3-5$ & First & Free swimming & $10: 00-16: 00$ & $\mathrm{ME} \rightarrow \mathrm{AC} \rightarrow \mathrm{SR} \rightarrow \mathrm{DA} \rightarrow \mathrm{OR}$ & idTracker software \\
Wang et al., 2020 & 5 & First & Free swimming & - & $\mathrm{ME} \rightarrow \mathrm{AC} \rightarrow \mathrm{SR} \rightarrow \mathrm{DA} \rightarrow \mathrm{OR}$ & ImageJ software \\
Yang et al., 2020 & - & - & Free swimming & - & $\mathrm{ME} \rightarrow \mathrm{SR} \rightarrow \mathrm{DA} \rightarrow \mathrm{OR}$ & Image Pro Plus software \\
Yin et al., 2019 & - & First & Free swimming & $9: 00-10: 00$ & $\mathrm{ME} \rightarrow \mathrm{SR} \rightarrow \mathrm{DA} \rightarrow \mathrm{OR}$ & Image Pro software \\
Zhang et al., 2020b & 10 & First & Free swimming & $11: 30-12: 30$ & $\mathrm{ME} \rightarrow \mathrm{AC} \rightarrow \mathrm{SR} \rightarrow \mathrm{DA} \rightarrow \mathrm{OR}$ & EthoVision 12 software \\
Zhang et al., 2021 & 10 & First & Free swimming & $13: 30-16: 00$ & $\mathrm{ME} \rightarrow \mathrm{AC} \rightarrow \mathrm{SR} \rightarrow \mathrm{DA} \rightarrow \mathrm{OR}$ & EthoVision XT 11.5 software
\end{tabular}

${ }^{\text {a }}$ The abbreviations of ME, MA, AC, SR, DA and OR represented microplastic exposure, mortality analysis, acclimation, swimming recoded, data analysis and obtaining result, respectively. 
environmentally relevant concentrations, which may provide potential mechanistic bases for understanding MPs-induced locomotor activity decline (Wright et al., 2013b; Paul-Pont et al., 2016; Barboza et al., 2018b; Ding et al., 2018; Jin et al., 2018; Limonta et al., 2019; Wan et al., 2019; Yin et al., 2019; Li et al., 2020c; Tang et al., 2020; Yang et al., 2020; Zhao et al., 2020).

\subsubsection{Energy reserve reduction}

Yin et al. (2019) investigated the effects of 14-day exposure to $15 \mu \mathrm{m}$ PS MPs $(190 \mu \mathrm{g} / \mathrm{L})$ on the energy reserve and nutritional quality of $S$. schlegelii, indicating that the gross energy, crude protein and crude lipid dramatically reduced by $9 \%, 3 \%$ and $27 \%$, respectively, compared with the control group. Similar effects on this species also appeared when exposed to $0.5 \mu \mathrm{m}$ PS MPs for 14 days (Fig. 5a) (Yin et al., 2019). Consistently, the lugworm Arenicola marina significantly depleted the lipid reserves by up to $50 \%$ when exposed to polyvinyl chloride (PVC) MPs for 4 weeks at environmentally relevant concentrations, accompanied by obvious reduction of feeding activity (Wright et al., 2013b). Therefore, the ingestion and bioaccumulation of MPs could cause gut blockage and pseudo-physical satiety, inhibit food intake, thereby reducing the energy reserve, and consequently, limiting the necessary energy supply for the locomotor activity of aquatic organisms (Watts et al., 2015; Rotjan et al., 2019; da Costa Araújo and Malafaia, 2020).

\subsubsection{Metabolism disorder}

Zhao et al. (2020) exposed zebrafish to $100 \mu \mathrm{g} / \mathrm{L}$ of $5 \mu \mathrm{m}$ PS MPs for 21 days to evaluate the effect of MPs on the glycolipid metabolism in the liver. Results showed that the levels of major biomarkers tended to decrease in the MPs-treated group, and the levels of glucose, $\alpha$-ketoglutaric acid, isocitrate dehydrogenase, aldehyde dehydrogenase 9 family member A1a (ALDH9A1A), enoyl-coenzyme A, hydratase/ 3-hydroxyacyl coenzyme A dehydrogenase (EHHADH) and aldehyde dehydrogenese- $2 * 2(A L D H 2 * 2)$ obviously decreased by $47 \%, 40 \%$, $33 \%, 71 \%, 73 \%$ and $70 \%$, respectively, indicating the disruption of the hepatic glycolipid metabolism (Fig. 5b). Correspondingly, the transcriptome and Kyoto Encyclopedia of Genes and Genomes (KEGG) pathway analyses identified that MP exposure mainly affected the carbon metabolism, amino acid metabolism and lipid metabolism pathways, with 1388 differentially expressed genes (756 down-regulated and 632 up-regulated). Similar findings were reported by Limonta et al. (2019), showing that one of the main effects of MPs on the gene transcription of zebrafish was down-regulation of the energy metabolism pathways. Therefore, MP exposure disrupted the energy homeostasis and inhibited the energy metabolism, resulting in the shortage of energy supply during the endurance locomotion of aquatic organisms (Cedervall et al., 2012; Mattsson et al., 2015; Zhao et al., 2020).

\subsubsection{Gut microbiota dysbiosis}

Gut microbiota is composed by various types of microorganisms inhabiting the intestines of animals (Kamada et al., 2013; Nieuwdorp et al., 2014). Wan et al. (2019) explored the effects of two sizes (5 and $50 \mu \mathrm{m})$ of PS MPs $(1 \mathrm{mg} / \mathrm{L})$ on the abundance and diversity of gut microbiota in zebrafish. It was shown that MP exposure obviously changed the structure of gut microbiome, which was reflected in the remarkably decreased abundances of Bacteroidetes and $\gamma$-Proteobacteria in both MPs-treated groups, and the significantly increased abundance of Firmicutes in $50 \mu \mathrm{m}$ MPs-treated group (Fig. 5c). The following principal coordinate analysis (PCA) also revealed the alterations of the main components of gut microbiome in MP treatment groups. Consistently, Li et al., (2020c) also reported the dysbiosis of gut microbiota in Mytilus edulis induced by MPs at environmentally realistic concentration $(200 \mu \mathrm{g} / \mathrm{L})$, identifying 45 operational taxonomic units (OTUs) that had significant difference in the abundance of microbiota after MP exposure (20 OTUs increased and 25 OTUs decreased). Increasing evidence indicated that the gut microbiota had substantial influence on host energy harvest, energy metabolism, weight regulation and behavior modulation, and its dysbiosis was harmful to host health and further influenced the locomotor activity (Mayer, 2011; Glenny et al., 2017).

\subsubsection{Inflammation response}

In order to determine the impacts of MPs on several inflammatory cytokines in the gut, zebrafish were exposed to $1 \mathrm{mg} / \mathrm{L}$ of two sizes $(0.5 \mu \mathrm{m}$ and $50 \mu \mathrm{m})$ of PS MPs for 14 days (Jin et al., 2018). It was shown that $0.5 \mu \mathrm{m}$ MPs not only significantly increased the mRNA levels of interleukin-1 $\alpha(I L-1 \alpha)$ (2.4-fold), interleukin-1 $\beta$ ( $I L-1 \beta)$ (4.3-fold) and interferon (IFN) (2.4-fold), but also remarkably enhanced their protein levels (3.2-, 3.4-, 1.2-fold, respectively), and $50 \mu \mathrm{m}$ MPs obviously improved the mRNA level of IFN (2.3-fold) and the protein level of IL- $1 \alpha$ (2.7-fold) (Fig. 5d), suggesting the occurrence of inflammation in the gut of zebrafish after MP exposure. It seemed that MPs could easily induce the inflammation response in zebrafish, because a remarkable expression of IL-1 $\alpha$ was observed at a very low exposure concentration (10 $\mu \mathrm{g} / \mathrm{L})$ (Qiao et al., 2019a). For other species, Wright et al. (2013b) also reported the appearance of inflammation response in A. marina, which was represented by the significantly increased phagocytic cells after MP exposure. The inflammation response might be due to the physical damage caused by the blockage of MPs in the gut (Wan et al., 2019). Qiao et al. (2019b) observed obvious histological changes (78\%$86 \%)$ in the MPs-treated ( $50 \mu \mathrm{g} / \mathrm{L}-500 \mu \mathrm{g} / \mathrm{L})$ gut tissues, which were mainly manifested as bowel wall thinning, villi injury and epithelial damage. Besides that, the gut microbiota dysbiosis has been demonstrated to be closely associated with the inflammation response (Fackelmann and Sommer, 2019). Previous studies suggested that the inflammation response could inhibit the locomotor activity, as organisms with inflammation had decreased food intake, metabolic rate, body weight and fat content (Schneiders et al., 2015; Pirsaheb et al., 2020; Solomando et al., 2020).

\subsubsection{Neurotoxic response}

The locomotor activity is mainly regulated by the central nervous system (CNS) and generally serves as a sensitive indicator of neurotoxicity (Selderslaghs et al., 2010; Haijima et al., 2017). The decline of locomotor performance suggested the occurrence of MP-induced neurotoxicity. Evidently, Ding et al. (2018) continuously monitored the changes of acetylcholinesterase (AChE) activity, a key neurotransmitter enzyme indicating neurotoxicity, in the brain of Oreochromis niloticus during a 14-day exposure to $0.1 \mu \mathrm{m}$ PS MPs at the concentrations of 1,10 , and $100 \mu \mathrm{g} / \mathrm{L}$. Obvious neurotoxicity was observed as indicated by the significant reductions of AChE activities at all exposure concentrations, with the maximum inhibition rates of $37.7 \%$ on the 3 rd day after 10 and $100 \mu \mathrm{g} / \mathrm{L}$ MP exposure (Fig. 5e). Similarly, when Tegillarca granosa was exposed to $1 \mathrm{mg} / \mathrm{L}$ PS MPs for 14 days, the expression levels of genes encoding neurotransmitter modulatory enzymes ( $A C h E$, monoamine oxidase $(M A O)$ and gamma-aminobutyric acid transaminase (GABAT)) and receptors (muscarinic acetylcholine receptor M3 (mAChR3), dopamine receptor D3 (DRD3) and gamma-aminobutyric acid type A receptor subunit delta $(G A B A D)$ ) tended to decrease, among which $D R D 3$ and GABAD decreased significantly, up to $49 \%$ and $69 \%$, respectively, implying the evident neurotoxicity (Tang et al., 2020). The inhibitions of neurotransmitter modulatory enzymes and receptors would cause a marked accumulation of acetylcholine in the brain, and ultimately interfered with the function of neurons involved in the motor modulation (e.g. cholinergic and gamma-aminobutyric acidergic (GABAergic) neurons), resulting in the dysfunction of neural connections and the decline of muscular control, thereby impairing the locomotor performance of aquatic organisms (Pereira et al., 2012; Chen et al., 2017a; Zhang et al., 2020a).

\subsubsection{Oxidative stress}

The oxidative stress has been proposed as a key mechanism underlying MPs-induced locomotor activity decline in aquatic organisms (Paul-Pont et al., 2016; Chen et al., 2017a; Barboza et al., 2018b; Yang 
a

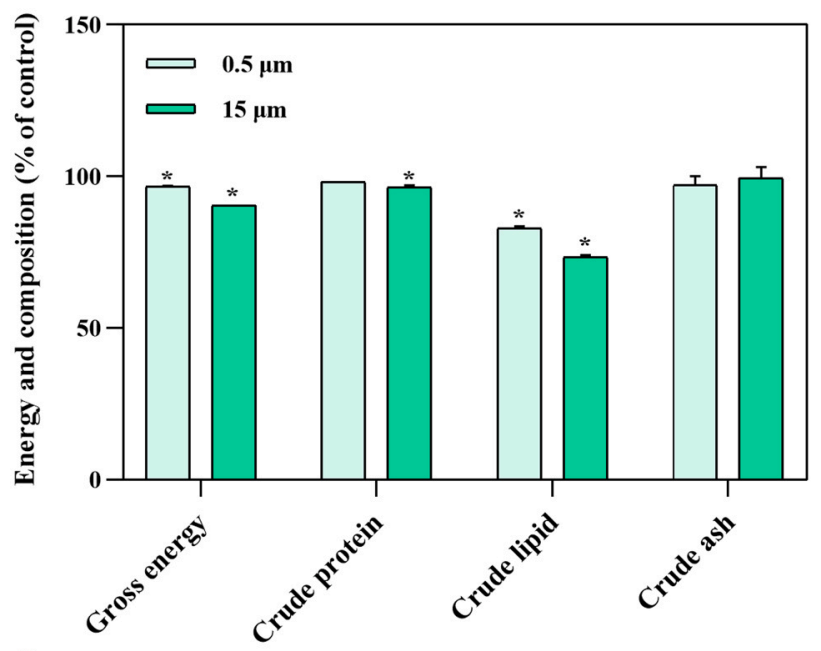

c

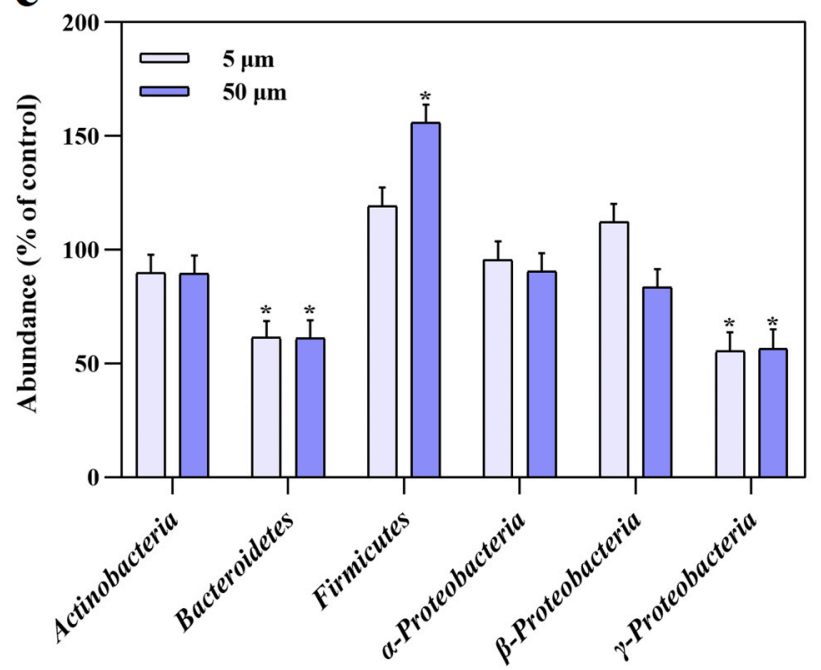

e

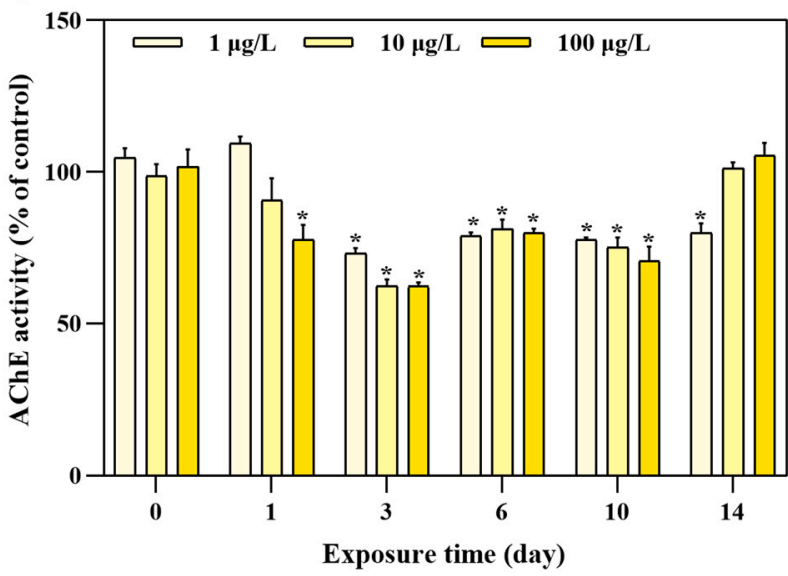

b

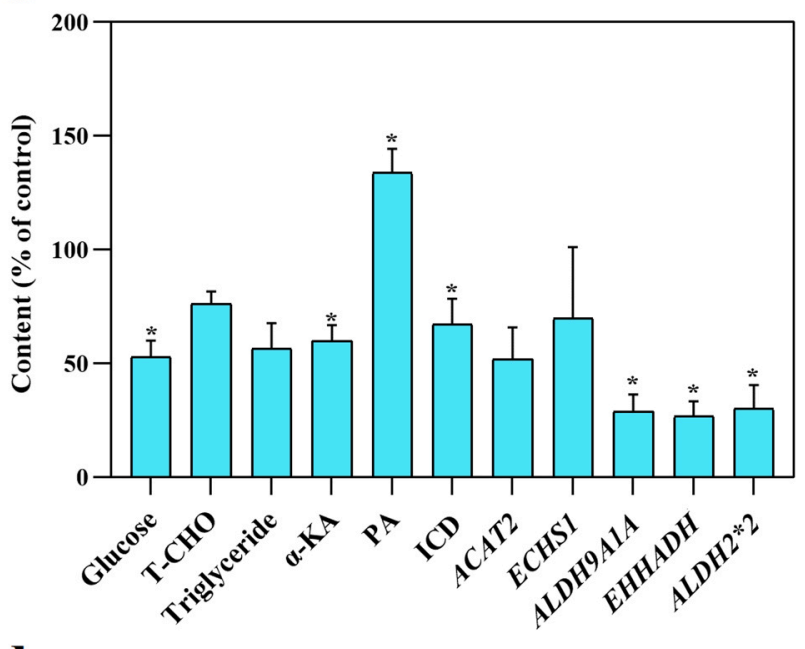

d

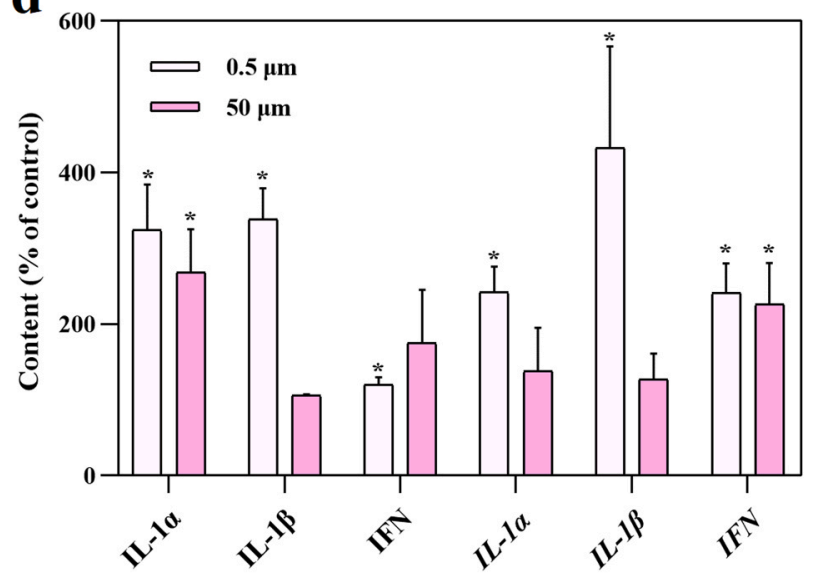

f

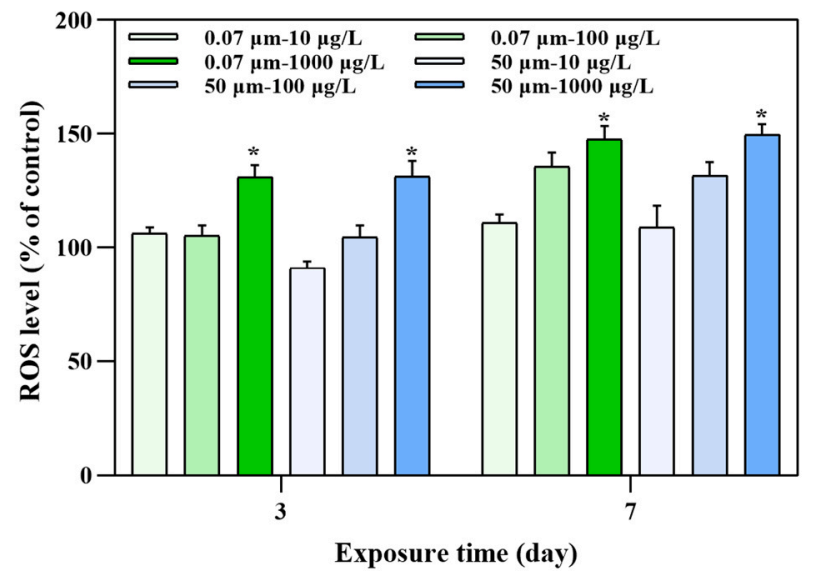

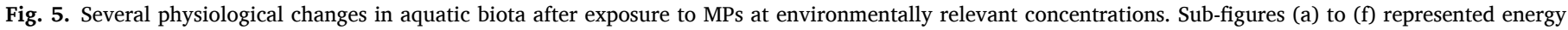

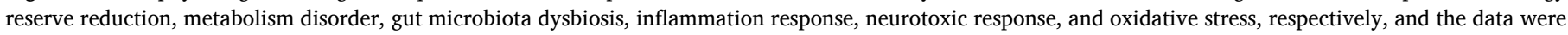

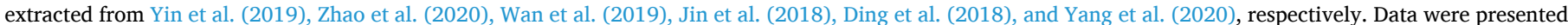

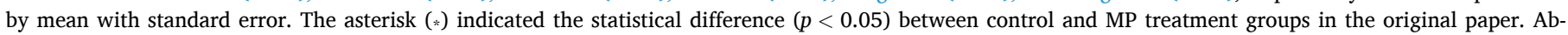

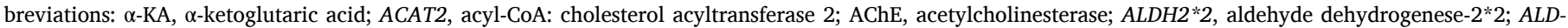

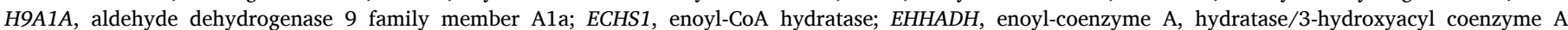

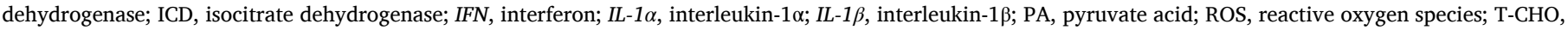
total cholesterol. 
et al., 2020). According to the PCA and multiple linear regression analyses by Chen et al. (2017a), after exposure to $1 \mathrm{mg} / \mathrm{L}$ MPs for 5 days, the major antioxidant biomarkers constituted a principal component that significantly influenced the locomotor performance of zebrafish. Consistently, Yang et al. (2020) reported the simultaneous appearances of velocity inhibition ( $6 \%$ on average) and ROS increase $(21 \%$ on average) in Carassius auratus after exposure to two sizes of MPs (5 and $50 \mu \mathrm{m})$ at environmentally relevant concentrations (10, 100 and $1000 \mu \mathrm{g} / \mathrm{L}$ ) for 3 and 7 days, implying a potential link between oxidative stress and locomotor defect (Fig. 5f). Paul-Pont et al. (2016) also indicated that exposure of mussels (Mytilus spp.) to $32 \mu \mathrm{g} / \mathrm{L}$ PS MPs (2-6 $\mu \mathrm{m}$ ) for 7 days could trigger the substantial modulation of oxidative balance, which was characterized by the increased production of ROS and enhanced expression of antioxidant and glutathione-related enzymes. In addition, the neurotoxicity of MPs is generally associated with oxidative stress, due to the high vulnerability of CNS to lipid peroxidation (LPO). LPO is a self-propagating autocatalytic reaction leading to the oxidative damage of lipoproteins, cell membranes and other lipid-containing structures (Khan et al., 2019). Barboza et al. (2018b) found that after Dicentrarchus labrax was exposed to $690 \mu \mathrm{g} / \mathrm{L} \mathrm{MPs}$ $(1-5 \mu \mathrm{m})$ for $96 \mathrm{~h}$, the LPO level in the brain significantly increased by $118 \%$, while the AChE activity obviously decreased by $50 \%$, indicating that MP exposure induced oxidative stress and lipid damage in the brain, and subsequently contributed to neurotoxicity affecting the locomotor activity (Salminen and Paul, 2014; Barboza et al., 2018b; Prokić et al., 2019).

\section{Conclusions}

This study provided a robust evidence that MPs at environmentally relevant concentrations $(\leq 1 \mathrm{mg} / \mathrm{L}$, median $=0.125 \mathrm{mg} / \mathrm{L}$ ) significantly decreased the average speed and moved distance of aquatic biota by $5 \%$ and $8 \%$, respectively, resulting in an obvious reduction of the locomotor performance by $6 \%$. The MPs-induced alterations in locomotor activity were influenced by many factors, presenting size-, time-, concentrationdependent manners and multi-factors interactions. Moreover, the biological effect of MPs on locomotor activity was not species-specific among the tested organisms, highlighting the broader influence/ threat/risk of MPs on the aquatic environment. In addition, the MPsinduced locomotor activity decline may be related to multiple physiological changes of aquatic organisms after exposure to MPs, including energy reserve reduction, metabolism disorder, gut microbiota dysbiosis, inflammation response, neurotoxic response, and oxidative stress. This work offered a robust analysis to assess the behavioral toxicity of MPs at environmentally relevant concentrations, contributing to understanding the health/environmental/ecological risk of MPs in the natural environment.

\section{CRediT authorship contribution statement}

Tao Sun: Methodology, Formal analysis, Writing - original draft. Junfei Zhan: Formal analysis. Fei Li: Writing - review \& editing. Chenglong Ji: Writing - review \& editing. Huifeng Wu: Supervision, Writing - review \& editing, Project administration.

\section{Declaration of Competing Interest}

The authors declare that they have no known competing financial interests or personal relationships that could have appeared to influence the work reported in this paper.

\section{Acknowledgments}

This research was supported by the grants from National Natural Science Foundation of China (42076164) and the Young Taishan Scholars Program of Shandong Province for Prof. Huifeng Wu (tsqn201812115).

\section{Appendix A. Supporting information}

Supplementary data associated with this article can be found in the online version at doi:10.1016/j.jhazmat.2021.125581.

\section{References}

Akdogan, Z., Guven, B., 2019. Microplastics in the environment: a critical review of current understanding and identification of future research needs. Environ. Pollut. 254, 113011.

Alomar, C., Deudero, S., Compa, M., Guijarro, B., 2020. Exploring the relation between plastic ingestion in species and its presence in seafloor bottoms. Mar. Pollut. Bull. $160,111641$.

Anbumani, S., Kakkar, P., 2018. Ecotoxicological effects of microplastics on biota: a review. Environ. Sci. Pollut. Res. 25, 14373-14396.

Arciga, S.M.B., Soliman, V.S., 2020. Microplastics reduce the growth of exposed marine invertebrates: a meta-analysis. J. Fish. Environ. 44, 53-61.

Banaee, M., Soltanian, S., Sureda, A., Gholamhosseini, A., Haghi, B.N., Akhlaghi, M., Derikvandy, A., 2019. Evaluation of single and combined effects of cadmium and micro-plastic particles on biochemical and immunological parameters of common carp (Cyprinus carpio). Chemosphere 236, 124335.

Barboza, L.G.A., Vieira, L.R., Guilhermino, L., 2018a. Single and combined effects of microplastics and mercury on juveniles of the European seabass (Dicentrarchus labrax): changes in behavioural responses and reduction of swimming velocity and resistance time. Environ. Pollut. 236, 1014-1019.

Barboza, L.G.A., Vieira, L.R., Branco, V., Figueiredo, N., Carvalho, F., Carvalho, C., Guilhermino, L., 2018b. Microplastics cause neurotoxicity, oxidative damage and energy-related changes and interact with the bioaccumulation of mercury in the European seabass, Dicentrarchus labrax (Linnaeus, 1758). Aquat. Toxicol. 195, 49-57.

Besseling, E., Redondo-Hasselerharm, P., Foekema, E.M., Koelmans, A.A., 2019. Quantifying ecological risks of aquatic micro- and nanoplastic. Crit. Rev. Environ. Sci. Technol. 49, 32-80.

Botterell, Z.L.R., Beaumont, N., Dorrington, T., Steinke, M., Thompson, R.C., Lindeque, P. K., 2019. Bioavailability and effects of microplastics on marine zooplankton: a review. Environ. Pollut. 245, 98-110.

Bringer, A., Thomas, H., Prunier, G., Dubillot, E., Bossut, N., Churlaud, C., Clérandeau, C., Le Bihanic, F., Cachot, J., 2020. High density polyethylene (HDPE) microplastics impair development and swimming activity of Pacific oyster D-larvae, Crassostrea gigas, depending on particle size. Environ. Pollut. 260, 113978.

Bucci, K., Tulio, M., Rochman, C.M., 2020. What is known and unknown about the effects of plastic pollution: a meta-analysis and systematic review. Ecol. Appl. 30, e02044.

Burns, E.E., Boxall, A.B.A., 2018. Microplastics in the aquatic environment: evidence for or against adverse impacts and major knowledge gaps. Environ. Toxicol. Chem. 37, 2776-2796.

Calabrese, E.J., 2014. Hormesis: a fundamental concept in biology. Microb. Cell 1, $145-149$.

Cedervall, T., Hansson, L.A., Lard, M., Frohm, B., Linse, S., 2012. Food chain transport of nanoparticles affects behaviour and fat metabolism in fish. PLoS One 7, e32254.

Chen, J., Luo, Y., Li, J., Zhou, X., Cao, J., Wang, R.W., Wang, Y., Shelton, S., Jin, Z., Walker, L.M., Feng, Z., Niu, S., Feng, W., Jian, S., Zhou, L., 2017b. Costimulation of soil glycosidase activity and soil respiration by nitrogen addition. Glob. Chang. Biol. 23, 1328-1337.

Chen, Q., Gundlach, M., Yang, S., Jiang, J., Velki, M., Yin, D., Hollert, H., 2017a. Quantitative investigation of the mechanisms of microplastics and nanoplastics toward zebrafish larvae locomotor activity. Sci. Total. Environ. 584-585, 1022-1031.

Chen, Q., Lackmann, C., Wang, W., Seiler, T.B., Hollert, H., Shi, H., 2020. Microplastics lead to hyperactive swimming behaviour in adult zebrafish. Aquat. Toxicol. 224, 105521.

Cole, J.H., 2020. Multimodality neuroimaging brain-age in UK biobank: relationship to biomedical, lifestyle, and cognitive factors. Neurobiol. Aging 92, 34-42.

Cole, M., Lindeque, P., Fileman, E., Halsband, C., Galloway, T.S., 2015. The impact of polystyrene microplastics on feeding, function and fecundity in the marine copepod Calanus helgolandicus. Environ. Sci. Technol. 49, 1130-1137.

Colwill, R.M., Creton, R., 2011. Locomotor behaviors in zebrafish (Danio rerio) larvae. Behav. Process. 86, 222-229.

Costa, E., Gambardella, C., Piazza, V., Vassalli, M., Sbrana, F., Lavorano, S., Garaventa, F., Faimali, M., 2020. Microplastics ingestion in the ephyra stage of Aurelia sp. triggers acute and behavioral responses. Ecotoxicol. Environ. Saf. 189, 109983.

da Costa Araújo, A.P., Malafaia, G., 2020. Can short exposure to polyethylene microplastics change tadpoles' behavior? A study conducted with neotropical tadpole species belonging to order anura (Physalaemus cuvieri). J. Hazard. Mater. 391, 122214.

da Silva Souza, J.G., Libeck, L.T., do Carmo Rodrigues Virote, B., Egger, R.C., de Sá, G.C. R., Machado, G.J., Murgas, L.D.S., 2020. A method to analyze the relationship between locomotor activity and feeding behaviour in larvae of Betta splendens. Aquac. Int 28, 1141-1152. 
De Felice, B., Sabatini, V., Antenucci, S., Gattoni, G., Santo, N., Bacchetta, R., Ortenzi, M. A., Parolini, M., 2019. Polystyrene microplastics ingestion induced behavioral effects to the cladoceran Daphnia magna. Chemosphere 231, 423-431.

De Stefano, A., Jacobson, M.G., 2018. Soil carbon sequestration in agroforestry systems: a meta-analysis. Agrofor. Syst. 92, 285-299.

Ding, J., Zhang, S., Razanajatovo, R.M., Zou, H., Zhu, W., 2018. Accumulation, tissue distribution, and biochemical effects of polystyrene microplastics in the freshwater fish red tilapia (Oreochromis niloticus). Environ. Pollut. 238, 1-9.

Ebrahimi, E., Kamrani, E., Heydarnejad, M.S., Safari, O., 2017. Daily rhythms of locomotor and demand-feeding activities in Schizothorax pelzami (Kessler, 1870). Chronobiol. Int. 34, 1366-1376.

Egger, M., Smith, G.D., Schneider, M., Minder, C., 1997. Bias in meta-analysis detected by a simple, graphical test. BMJ 315, 629-634.

Fackelmann, G., Sommer, S., 2019. Microplastics and the gut microbiome: how chronically exposed species may suffer from gut dysbiosis. Mar. Pollut. Bull. 143, 193-203.

Fok, L., Lam, T.W.L., Li, H.X., Xu, X.R., 2020. A meta-analysis of methodologies adopted by microplastic studies in China. Sci. Total Environ. 718, 135371.

Foley, C.J., Feiner, Z.S., Malinich, T.D., Höök, T.O., 2018. A meta-analysis of the effects of exposure to microplastics on fish and aquatic invertebrates. Sci. Total. Environ. 631-632, 550-559.

Fonte, E., Ferreira, P., Guilhermino, L., 2016. Temperature rise and microplastics interact with the toxicity of the antibiotic cefalexin to juveniles of the common goby (Pomatoschistus microps): post-exposure predatory behaviour, acetylcholinesterase activity and lipid peroxidation. Aquat. Toxicol. 180, 173-185.

Fossi, M.C., Coppola, D., Baini, M., Giannetti, M., Guerranti, C., Marsili, L., Panti, C., de Sabata, E., Clò, S., 2014. Large filter feeding marine organisms as indicators of microplastic in the pelagic environment: the case studies of the Mediterranean basking shark (Cetorhinus maximus) and fin whale (Balaenoptera physalus). Mar. Environ. Res. 100, 17-24.

Gambardella, C., Morgana, S., Ferrando, S., Bramini, M., Piazza, V., Costa, E., Garaventa, F., Faimali, M., 2017. Effects of polystyrene microbeads in marine planktonic crustaceans. Ecotoxicol. Environ. Saf. 145, 250-257.

Gambardella, C., Morgana, S., Bramini, M., Rotini, A., Manfra, L., Migliore, L., Piazza, V., Garaventa, F., Faimali, M., 2018. Ecotoxicological effects of polystyrene microbeads in a battery of marine organisms belonging to different trophic levels. Mar. Environ. Res. 141, 313-321.

Garcés-Ordóñez, O., Mejía-Esquivia, K.A., Sierra-Labastidas, T., Patiño, A., Blandón, L. M., Díaz, L.F.E., 2020. Prevalence of microplastic contamination in the digestive tract of fishes from mangrove ecosystem in Cispata, Colombian Caribbean. Mar. Pollut. Bull. 154, 111085.

Gerlai, R., 2014. Social behavior of zebrafish: from synthetic images to biological mechanisms of shoaling. J. Neurosci. Methods 234, 59-65.

Glenny, E.M., Bulik-Sullivan, E.C., Tang, Q., Bulik, C.M., Carroll, I.M., 2017. Eating disorders and the intestinal microbiota: mechanisms of energy homeostasis and behavioral influence. Curr. Psychiatry Rep. 19, 51.

Gu, L., Tian, L., Gao, G., Peng, S., Zhang, J., Wu, D., Huang, J., Hua, Q., Lu, T., Zhong, L., Fu, Z., Pan, X., Qian, H., Sun, L., 2020. Inhibitory effects of polystyrene microplastics on caudal fin regeneration in zebrafish larvae. Environ. Pollut. 266, 114664.

Gurevitch, J., Koricheva, J., Nakagawa, S., Stewart, G., 2018. Meta-analysis and the science of research synthesis. Nature 555, 175-182.

Guven, O., Bach, L., Munk, P., Dinh, K.V., Mariani, P., Nielsen, T.G., 2018. Microplastic does not magnify the acute effect of PAH pyrene on predatory performance of a tropical fish (Lates calcarifer). Aquat. Toxicol. 198, 287-293.

Haijima, A., Lesmana, R., Shimokawa, N., Amano, I., Takatsuru, Y., Koibuchi, N., 2017. Differential neurotoxic effects of in utero and lactational exposure to hydroxylated polychlorinated biphenyl (OH-PCB 106) on spontaneous locomotor activity and motor coordination in young adult male mice. J. Toxicol. Sci. 42, 407-416.

Han, M., Niu, X., Tang, M., Zhang, B.T., Wang, G., Yue, W., Zhu, J., 2020. Distribution of microplastics in surface water of the lower Yellow River near estuary. Sci. Total Environ. 707, 135601.

Hedges, L.V., Gurevitch, J., Curtis, P.S., 1999. The meta-analysis of response ratios in experimental ecology. Ecology 80, 1150-1156.

Higgins, J.P.T., Thomas, J., Chandler, J., Cumpston, M., Li, T., Page, M.J., Welch, V.A., 2020. Cochrane Handbook for Systematic Reviews of Interventions version 6.1 (updated September 2020). https://training.cochrane.org/handbook

Horn, D.A., Granek, E.F., Steele, C.L., 2020. Effects of environmentally relevant concentrations of microplastic fibers on Pacific mole crab (Emerita analoga) mortality and reproduction. Limnol. Oceanogr. 5, 74-83.

Hu, Q., Wang, H., He, C., Jin, Y., Fu, Z., 2021. Polystyrene nanoparticles trigger the activation of p38 MAPK and apoptosis via inducing oxidative stress in zebrafish and macrophage cells. Environ. Pollut. 269, 116075.

Jeong, C.B., Won, E.J., Kang, H.M., Lee, M.C., Hwang, D.S., Hwang, U.K., Zhou, B., Souissi, S., Lee, S.J., Lee, J.S., 2016. Microplastic size-dependent toxicity, oxidative stress induction, and p-JNK and p-p38 activation in the monogonont rotifer (Brachionus koreanus). Environ. Sci. Technol. 50, 8849-8857.

Jin, Y., Xia, J., Pan, Z., Yang, J., Wang, W., Fu, Z., 2018. Polystyrene microplastics induce microbiota dysbiosis and inflammation in the gut of adult zebrafish. Environ. Pollut. 235, 322-329.

Kamada, N., Seo, S.U., Chen, G.Y., Núñez, G., 2013. Role of the gut microbiota in immunity and inflammatory disease. Nat. Rev. Immunol. 13, 321-335.

Khan, B., Adeleye, A.S., Burgess, R.M., Russo, S.M., Ho, K.T., 2019. Effects of graphene oxide nanomaterial exposures on the marine bivalve, Crassostrea virginica. Aquat. Toxicol. 216, 105297.
Krylov, V.V., Izvekov, E.I., Pavlova, V.V., Pankova, N.A., Osipova, E.A., 2020. Circadian rhythms in zebrafish (Danio rerio) behaviour and the sources of their variability. Biol. Rev., brv.12678 https://doi.org/10.1111/brv.12678.

Leslie, H.A., Brandsma, S.H., van Velzen, M.J.M., Vethaak, A.D., 2017. Microplastics en route: field measurements in the Dutch river delta and Amsterdam canals, wastewater treatment plants, North Sea sediments and biota. Environ. Int. 101, $133-142$.

Li, L.L., Amara, R., Souissi, S., Dehaut, A., Duflos, G., Monchy, S., 2020c. Impacts of microplastics exposure on mussel (Mytilus edulis) gut microbiota. Sci. Total Environ. 745, 141018.

Li, Y., Wang, J., Yang, G., Lu, L., Zheng, Y., Zhang, Q., Zhang, X., Tian, H., Wang, W., $\mathrm{Ru}, \mathrm{S}$., 2020b. Low level of polystyrene microplastics decreases early developmental toxicity of phenanthrene on marine medaka (Oryzias melastigma). J. Hazard. Mater. $385,121586$.

Li, R., Yu, L., Chai, M., Wu, H., Zhu, X., 2020a. The distribution, characteristics and ecological risks of microplastics in the mangroves of Southern China. Sci. Total Environ. 708, 135025.

Limonta, G., Mancia, A., Benkhalqui, A., Bertolucci, C., Abelli, L., Fossi, M.C., Panti, C., 2019. Microplastics induce transcriptional changes, immune response and behavioral alterations in adult zebrafish. Sci. Rep. 9, 15775.

Mattsson, K., Ekvall, M.T., Hansson, L.A., Linse, S., Malmendal, A., Cedervall, T., 2015. Altered behavior, physiology, and metabolism in fish exposed to polystyrene nanoparticles. Environ. Sci. Technol. 49, 553-561.

Mayer, E., 2011. Gut feelings: the emerging biology of gut-brain communication. Nat. Rev. Neurosci. 12, 453-466.

Mazidi, M., Rezaie, P., Karimi, E., Kengne, A.P., 2017. The effects of bile acid sequestrants on lipid profile and blood glucose concentrations: a systematic review and meta-analysis of randomized controlled trials. Int. J. Cardiol. 227, 850-857.

Miller, M.E., Hamann, M., Kroon, F.J., 2020. Bioaccumulation and biomagnification of microplastics in marine organisms: a review and meta-analysis of current data. PLoS One 15, e0240792.

von Moos, N., Burkhardt-Holm, P., Köhler, A., 2012. Uptake and effects of microplastics on cells and tissue of the blue mussel Mytilus edulis L. after an experimental exposure. Environ. Sci. Technol. 46, 11327-11335.

Naidoo, T., Glassom, D., 2019. Decreased growth and survival in small juvenile fish, after chronic exposure to environmentally relevant concentrations of microplastic. Mar. Pollut. Bull. 145, 254-259.

Nieuwdorp, M., Gilijamse, P.W., Pai, N., Kaplan, L.M., 2014. Role of the microbiome in energy regulation and metabolism. Gastroenterology 146, 1525-1533.

Nobre, C.R., Moreno, B.B., Alves, A.V., de Lima Rosa, J., da Rosa Franco, H., de Souza Abessa, D.M., Maranho, L.A., Choueri, R.B., Gusso-Choueri, P.K., Pereira, C.D.S., 2020. Effects of microplastics associated with Triclosan on the oyster Crassostrea brasiliana: an integrated biomarker approach. Arch. Environ. Contam. Toxicol. 79, $101-110$.

Pang, X., Yuan, X.Z., Cao, Z.D., Fu, S.J., 2014. The effects of fasting on swimming performance in juvenile qingbo (Spinibarbus sinensis) at two temperatures. J. Therm. Biol. 42, 25-32.

Patel, N., Khan, Md.Z.A., Shahane, S., Rai, D., Chauhan, D., Kant, C., Chaudhary, V.K., 2020. Emerging pollutants in aquatic environment: source, effect, and challenges in biomonitoring and bioremediation-A review. Pollution 6, 99-113.

Paul-Pont, I., Lacroix, C., Fernández, C.G., Hégaret, H., Lambert, C., Le Goïc, N., Frère, L., Cassone, A.L., Sussarellu, R., Fabioux, C., Guyomarch, J., Albentosa, M., Huvet, A., Soudant, P., 2016. Exposure of marine mussels Mytilus spp. to polystyrene microplastics: toxicity and influence on fluoranthene bioaccumulation. Environ. Pollut. 216, 724-737.

Pedà, C., Caccamo, L., Fossi, M.C., Gai, F., Andaloro, F., Genovese, L., Perdichizzi, A., Romeo, T., Maricchiolo, G., 2016. Intestinal alterations in European sea bass Dicentrarchus labrax (Linnaeus, 1758) exposed to microplastics: preliminary results. Environ. Pollut. 212, 251-256.

Pereira, V.M., Bortolotto, J.W., Kist, L.W., de Azevedo, M.B., Fritsch, R.S., da Luz Oliveira, R., Pereira, T.C.B., Bonan, C.D., Vianna, M.R., Bogo, M.R., 2012. Endosulfan exposure inhibits brain AChE activity and impairs swimming performance in adult zebrafish (Danio rerio). Neurotoxicology 33, 469-475.

Pirsaheb, M., Hossini, H., Makhdoumi, P., 2020. Review of microplastic occurrence and toxicological effects in marine environment: experimental evidence of inflammation. Process Saf. Environ. Prot. 142, 1-14.

Prokić, M.D., Radovanović, T.B., Gavrić, J.P., Faggio, C., 2019. Ecotoxicological effects of microplastics: examination of biomarkers, current state and future perspectives. Trends Anal. Chem. 111, 37-46.

Qiang, L., Cheng, J., 2019. Exposure to microplastics decreases swimming competence in larval zebrafish (Danio rerio). Ecotoxicol. Environ. Saf. 176, 226-233.

Qiao, R., Deng, Y., Zhang, S., Wolosker, M.B., Zhu, Q., Ren, H., Zhang, Y., 2019a. Accumulation of different shapes of microplastics initiates intestinal injury and gut microbiota dysbiosis in the gut of zebrafish. Chemosphere 236, 124334.

Qiao, R., Sheng, C., Lu, Y., Zhang, Y., Ren, H., Lemos, B., 2019b. Microplastics induce intestinal inflammation, oxidative stress, and disorders of metabolome and microbiome in zebrafish. Sci. Total. Environ. 662, 246-253.

Rist, S., Baun, A., Hartmann, N.B., 2017. Ingestion of micro- and nanoplastics in Daphnia magna-Quantification of body burdens and assessment of feeding rates and reproduction. Environ. Pollut. 228, 398-407.

Rotjan, R.D., Sharp, K.H., Gauthier, A.E., Yelton, R., Lopez, E.M.B., Carilli, J., Kagan, J. C., Urban-Rich, J., 2019. Patterns, dynamics and consequences of microplastic ingestion by the temperate coral, Astrangia poculata. Proc. R. Soc. B 286, 20190726.

de Ruijter, V.N., Redondo-Hasselerharm, P.E., Gouin, T., Koelmans, A.A., 2020. Quality criteria for microplastic effect studies in the context of risk assessment: a critical review. Environ. Sci. Technol. 54, 11692-11705. 
Saaristo, M., Brodin, T., Balshine, S., Bertram, M.G., Brooks, B.W., Ehlman, S.M., McCallum, E.S., Sih, A., Sundin, J., Wong, B.B.M., Arnold, K.E., 2018. Direct and indirect effects of chemical contaminants on the behaviour, ecology and evolution of wildlife. Proc. R. Soc. B 285, 20181297.

Salminen, L.E., Paul, R.H., 2014. Oxidative stress and genetic markers of suboptimal antioxidant defense in the aging brain: a theoretical review. Rev. Neurosci. 25, 805-819.

Sarasamma, S., Audira, G., Siregar, P., Malhotra, N., Lai, Y.H., Liang, S.T., Chen, J.R., Chen, K.H., Hsiao, C.D., 2020. Nanoplastics cause neurobehavioral impairments, reproductive and oxidative damages, and biomarker responses in zebrafish: throwing up alarms of wide spread health risk of exposure. Int. J. Mol. Sci. 21, 1410

Savović, J., Jones, H.E., Altman, D.G., Harris, R.J., Jüni, P., Pildal, J., Als-Nielsen, B., Balk, E.M., Gluud, C., Gluud, L.L., Ioannidis, J.P.A., Schulz, K.F., Beynon, R., Welton, N.J., Wood, L., Moher, D., Deeks, J.J., Sterne, J.A.C., 2012. Influence of reported study design characteristics on intervention effect estimates from randomised controlled trials: combined analysis of meta-epidemiological studies. Ann. Intern. Med. 157, 429-438.

Schneiders, J., Fuchs, F., Damm, J., Herden, C., Gerstberger, R., Soares, D.M., Roth, J., Rummel, C., 2015. The transcription factor nuclear factor interleukin 6 mediates pro- and anti-inflammatory responses during LPS-induced systemic inflammation in mice. Brain Behav. Immun. 48, 147-164.

Selderslaghs, I.W.T., Hooyberghs, J., De Coen, W., Witters, H.E., 2010. Locomotor activity in zebrafish embryos: a new method to assess developmental neurotoxicity. Neurotoxicol. Teratol. 32, 460-471.

Seuront, L., 2018. Microplastic leachates impair behavioural vigilance and predator avoidance in a temperate intertidal gastropod. Biol. Lett. 14, 20180453.

Shi, W., Han, Y., Sun, S., Tang, Y., Zhou, W., Du, X., Liu, G., 2020. Immunotoxicities of microplastics and sertraline, alone and in combination, to a bivalve species: sizedependent interaction and potential toxication mechanism. J. Hazard. Mater. 396, 122603.

Sievers, M., Hale, R., Parris, K.M., Melvin, S.D., Lanctôt, C.M., Swearer, S.E., 2019. Contaminant-induced behavioural changes in amphibians: a meta-analysis. Sci. Total Environ. 693, 133570.

Sıkdokur, E., Belivermiş, M., Sezer, N., Pekmez, M., Bulan, O.K., Kılıç, O., 2020. Effects of microplastics and mercury on manila clam Ruditapes philippinarum: feeding rate, immunomodulation, histopathology and oxidative stress. Environ. Pollut. 262, 114247.

Solomando, A., Capó, X., Alomar, C., Álvarez, E., Compa, M., Valencia, J.M., Pinya, S., Deudero, S., Sureda, A., 2020. Long-term exposure to microplastics induces oxidative stress and a pro-inflammatory response in the gut of Sparus aurata Linnaeus, 1758. Environ. Pollut. 266, 115295.

Tang, Y., Zhou, W., Sun, S., Du, X., Han, Y., Shi, W., Liu, G., 2020. Immunotoxicity and neurotoxicity of bisphenol A and microplastics alone or in combination to a bivalve species, Tegillarca granosa. Environ. Pollut. 265, 115115.

Tunali, M., Uzoefuna, E.N., Tunali, M.M., Yenigun, O., 2020. Effect of microplastics and microplastic-metal combinations on growth and chlorophyll a concentration of Chlorella vulgaris. Sci. Total Environ. 743, 140479.

Vera, L.M., Cairns, L., Sánchez-Vázquez, F.J., Migaud, H., 2009. Circadian rhythms of locomotor activity in the Nile tilapia Oreochromis niloticus. Chronobiol. Int. 26, 666-681.
Wan, Z., Wang, C., Zhou, J., Shen, M., Wang, X., Fu, Z., Jin, Y., 2019. Effects of polystyrene microplastics on the composition of the microbiome and metabolism in larval zebrafish. Chemosphere 217, 646-658.

Wang, X., Liu, L., Zheng, H., Wang, M., Fu, Y., Luo, X., Li, F., Wang, Z., 2020. Polystyrene microplastics impaired the feeding and swimming behavior of mysid shrimp Neomysis japonica. Mar. Pollut. Bull. 150, 110660.

Watts, A.J.R., Urbina, M.A., Shauna, C., Lewis, C., Galloway, T.S., 2015. Ingestion of plastic microfibers by the crab Carcinus maenas and its effect on food consumption and energy balance. Environ. Sci. Technol. 49, 14597-14604.

Wong, B.B.M., Candolin, U., 2015. Behavioral responses to changing environments. Behav. Ecol. 26, 665-673.

Wright, S.L., Thompson, R.C., Galloway, T.S., 2013a. The physical impacts of microplastics on marine organisms: a review. Environ. Pollut. 178, 483-492.

Wright, S.L., Rowe, D., Thompson, R.C., Galloway, T.S., 2013b. Microplastic ingestion decreases energy reserves in marine worms. Curr. Biol. 23, R1031-R1033.

Yang, H., Xiong, H., Mi, K., Xue, W., Wei, W., Zhang, Y., 2020. Toxicity comparison of nano-sized and micron-sized microplastics to Goldfish Carassius auratus Larvae. J. Hazard. Mater. 388, 122058.

Yin, L., Liu, H., Cui, H., Chen, B., Li, L., Wu, F., 2019. Impacts of polystyrene microplastics on the behavior and metabolism in a marine demersal teleost, black rockfish (Sebastes schlegelii). J. Hazard. Mater. 380, 120861.

Yu, J., Tian, J.Y., Xu, R., Zhang, Z.Y., Yang, G.P., Wang, X.D., Lai, J.G., Chen, R., 2020. Effects of microplastics exposure on ingestion, fecundity, development, and dimethylsulfide production in Tigriopus japonicus (Harpacticoida, copepod). Environ. Pollut. 267, 115429.

Zhang, P., Yan, Z., Lu, G., Ji, Y., 2019b. Single and combined effects of microplastics and roxithromycin on Daphnia magna. Environ. Sci. Pollut. Res. Int. 26, 17010-17020.

Zhang, R., Silic, M.R., Schaber, A., Wasel, O., Freeman, J.L., Sepúlveda, M.S., 2020b. Exposure route affects the distribution and toxicity of polystyrene nanoplastics in zebrafish. Sci. Total Environ. 724, 138065.

Zhang, S., Wang, J., Liu, X., Qu, F., Wang, X., Wang, X., Li, Y., Sun, Y., 2019a. Microplastics in the environment: a review of analytical methods, distribution, and biological effects. Trends Anal. Chem. 111, 62-72.

Zhang, Y., Wolosker, M.B., Zhao, Y., Ren, H., Lemos, B., 2020a. Exposure to microplastics cause gut damage, locomotor dysfunction, epigenetic silencing, and aggravate cadmium (Cd) toxicity in Drosophila. Sci. Total Environ. 744, 140979.

Zhang, Y.T., Chen, M., He, S., Fang, C., Chen, M., Li, D., Wu, D., Chernick, M., Hinton, D. E., Bo, J., Xie, L., Mu, J., 2021. Microplastics decrease the toxicity of triphenyl phosphate (TPhP) in the marine medaka (Oryzias melastigma) larvae. Sci. Total Environ. 763, 143040.

Zhao, Y., Bao, Z., Wan, Z., Fu, Z., Jin, Y., 2020. Polystyrene microplastic exposure disturbs hepatic glycolipid metabolism at the physiological, biochemical, and transcriptomic levels in adult zebrafish. Sci. Total Environ. 710, 136279.

Zhou, W., Han, Y., Tang, Y., Shi, W., Du, X., Sun, S., Liu, G., 2020. Microplastics aggravate the bioaccumulation of two waterborne veterinary antibiotics in an edible bivalve species: potential mechanisms and implications for human health. Environ. Sci. Technol. 54, 8115-8122.

Ziajahromi, S., Kumar, A., Neale, P.A., Leusch, F.D.L., 2018. Environmentally relevant concentrations of polyethylene microplastics negatively impact the survival, growth and emergence of sediment-dwelling invertebrates. Environ. Pollut. 236, 425-431. 